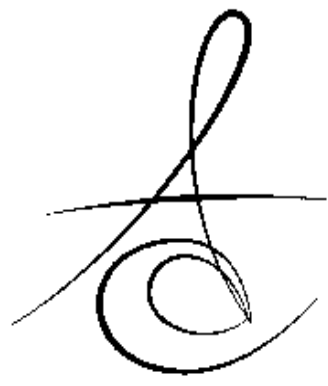

\title{
SONLU ELEMANLAR STRES ANALİZ YÖNTEMİ VE DENTAL İMPLANTOLOJİ ALANINDA YAPILAN ARAŞTIRMALAR
}

\section{FINITE ELEMENT STRESS ANALYSIS METHOD AND RESEARCHES ON DENTAL IMPLANTOLOGY}

\author{
Dr. Öğr. Üyesi Sercan KÜÇÜKKURT*
}

Makale Kodu/Article code: 3272

Makale Gönderilme tarihi: 09.01.2017

Kabul Tarihi; 13.07.2017

öz

Diş hekimliği dahil tüm tıp alanlarında, yapılması planlanan birçok çalışmanın, klinik şartlarda gerek etik nedenler gerek yüksek maliyetler ve gerekse teknik imkansızlıklar nedeniyle yapılabilmesi her zaman mümkün olmamaktadır. Aynı zamanda çalışmalar sırasında insan ya da hayvan faktörüne bağlı oluşan olumsuz durumlar ve aksaklıklar sonucu bu araştırmalar yarım kalabilmekte ve aynı çalışmayı birebir tekrar canlandırmak her zaman mümkün olmamaktadır. Mühendislik alanında uzun yıllardır kullanılmakta olan sonlu elemanlar stres analiz (SESA) yöntemi, diş hekimliği ve tıp alanlarında 40 yılı aşkın süredir bu tip imkansızIıkların önüne geçerek, normal şartlarda yapılması oldukça zor olan karmaşık çalışmaların bilgisayar ortamında kolaylıkla yapılabilmesini sağlamaktadır. SESA çalışmaları birebir aynı şartlarda ya da bazı değişiklikler yaparak farklı şekillerde sınırsız sayıda tekrarlanabilmektedir. Eski yıllarda ancak süper bilgisayar olarak adlandırılan endüstriyel bilgisayarlarla uygulanabilen SESA, son yıllarda bilgisayar alanında yaşanan hızlı teknolojik gelişmeler sayesinde eskiye nazaran, oldukça kolay şekilde, masasütü bilgisayarlarda uygulanabilmektedir. SESA özellikle mühendislik alanına benzer şekilde kuvvet, stres ve materyal bilimini de içeren dental implantoloji ile ilgili çalışmalarda birçok soruna hızlı ve kolay çözümler getirebilmektedir. SESA metodu sayesinde araştırılan konular hakkında hızlı ve güvenilir sonuçlar elde edilirken, birçok klinik çalışmanın yapılabilmesine de yol göstermekte ve ışık tutmaktadır. Bu derleme çalışmasında SESA yöntemi hakkında bilgi edinilmesi ve dental implantoloji alanında kullanılabilirliği ve güvenilirliği hakkında yapılmış çalışmaların incelenmesi amaçlanmıştır.

Anahtar Kelimeler: Sonlu eleman analiz yöntemi, SESA, Stres analizleri, Stres dağılımı, Diş implantları

\section{ABSTRACT}

In all branches of medicine, including dentistry, it is not always possible for many studies to be done in clinical conditions due to ethical reasons, high costs, and technical difficulties. Moreover, these studies may be interrupted due to human or animal related factors, and it is not always possible to revive the research under precisely the same conditions. Finite element analysis method (FEA), which has been used for many years in the engineering, has over 40 years in the dentistry and medicine, avoids this type of difficulties and makes it possible to efficiently perform complex tasks in a computer environment, that are difficult to perform under normal conditions. FEA studies can be repeated in an unlimited number, either on the same conditions or in different ways with some changes. FEA, which could only be applied with industrial computers which were called as a supercomputer in the past years, can be used easily on the desktop computers thanks to the rapid technological developments in the computers in recent years. This method can provide quick and easy solutions to many problems, especially in situations involving force, stress, and material science similar to engineering, such as dental implantology. While this method provides fast and reliable results on the subjects investigated, it also guides and illuminates the possibility of carrying out many clinical studies. In this review study, it is aimed to obtain information about FEA method and to examine the studies about usability and reliability in dental implantology.

Key Words: Finite Element Analysis, FEM, Stress Analysis, Stress distribution, Dental implants

*Istanbul Aydın Üniversitesi, Diş Hekimliği Fakültesi, Ağız, Diş ve Çene Cerrahisi AD Istanbul. 


\section{Sonlu Elemanlar Stres Analizi}

Sonlu elemanlar stres analizi (SESA) mühendislik alanında deneysel ortamda çözümü oldukça zor olan, ileri düzey teoremlerin bilgisayar yardımıla hesaplanarak, çözülebilmesini sağlayan bir analiz metodudur. Günümüzde tıp ve mühendisliğin birçok dalında kullanılmaktadır. Bu yöntemde basitçe, biyomekanik açıdan incelenmek istenen cisim belirli sayıda elemanlara bölünerek, analitik şekilde modellenir ve bu küçük parçalar üzerinde analizler gerçekleştirilir. SESA ile kararlı rejimli, değişken rejimli, linear (lineer), nonlinear (lineer olmayan) durumlar için; stres (gerilim) analizi, ISı transferi, akışkanlar mekaniği ve elektromanyetizma problemlerinin analizleri yapılabilir. ${ }^{1-5}$

SESA, sahip olduğu birçok avantaj sayesinde son yıllarda diş hekimliği ve dental implantoloji alanlarında sıklıkla tercih edilen bir araştırma yöntemi olmuştur. Klinik deneylerde bir çalışmanın birebir şartlarda tekrarlanması neredeyse olanaksızken, bu metodun arzu edildiği kadar tekrarlanabilmesi tekniğin önemli bir avantajıdır. ${ }^{6-9}$

SESA çeşitli bilgisayar yazılımları ile yapılmaktadır. Bu yazılımlar sayesinde cisimler üzerinde oluşan stres oluşumları, şekil ve yer değiştirme miktarları sayısal değerlere dönüştürülebilmektedir. Ayrıca bu verilerin daha kolay anlaşılması ve yorumlanması için renkli görüntülerin elde edilmesi de mümkün olmaktadır. İstenen bölgelerden alınan kesitlerde her rengin bir değer dizisini temsil etmesi sağlanmaktadır. Renk aralığına karşlık gelen değerler ise görüntülerde bir ölçek yardımıyla gösterilir. ${ }^{1,3,7,10}$

\section{SESA Prensipleri ve Uygulama Aşamaları}

SESA'da karmaşık sistem, idealize edilmiş bir "ağ (mesh)" ile tanımlanır. Ağ yapısını ise elemanlar (elements), bunlara bağlı düğüm noktaları (nodes) ve belirleyici sınır koşulları (boundary conditions) oluşturur. Ağı oluşturan çizgilerin kesim noktaları "düğüm noktaları" olarak adlandırılır. Bu ağı tanımlayan çizgiler arasında oluşan iki veya üç boyutlu unsurlara "sonlu eleman" adı verilir. Cismin boyut ve geometrisine göre elemanlara bölünmüş şekline ise "matematiksel model" denir.

Sınır koşulları, gerilmelerin ve yer değiştirmelerin sınır ifadelerini içerir. Başka bir deyişle, cismin nerede sabitlendiğini ve kuvvetin nereye uygulandığını gösterir. Analiz edilecek nesnenin durumuna ve uygulanacak kuvvetin yerine göre sınır koşulları belirlenmelidir. ${ }^{1-3,10}$
SESA uygulama aşamaları su şekildedir: ${ }^{1-5,8}$

1. İncelenecek cismin geometrisinin oluşturulması

2. Matematiksel modellerin oluşturulması

3. Malzeme özelliklerinin tanımlanması

4. Modelin sınır şartlarının ve uygulanacak yüklerin belirlenmesi

5. Yapılacak olan analiz tipinin seçilmesidir.

SESA metoduyla problemlerin çözülmesi için bilgisayara bazı verilerin girilmesi gereklidir. Bu veriler aşağıda sıralanmıştır: ${ }^{1-3,6}$

1. Nesnenin geometrisini oluşturacak koordinatlar,

2. Nesnenin geometrisi ve boyutu için uygun eleman türü,

3. Elemanlara ait poisson oranı ve elastisite modülü değerleri,

4. Oluşturulan modele uygulanacak kuvvetler,

5. Oluşturulan modelin sınır koşulları,

6. Gerçekleştirilecek analiz türü.

Oluşturulan matematiksel modelde, belirlenen kuvvetler ve sınır koşulları, düğüm noktalarına uygulandığında oluşan değişimsel durumlar için matrisler oluşturulur ve bu matrisler bilgisayar ortamında çözülür. 2, 3, 5, 9

Bir analizde sisteme tekil, yayılı veya kütle kuvvetleri etki edebilmektedir; Tekil kuvvetler, seçilen eleman ve düğüm noktalarına belirlenen açıda etki eden kuvvetlerdir, yaylı kuvvetler bir kenarda ya da bir alanda etkili olurlar, kütle kuvvetleri ise eleman hacmi için geçerli olan bir ağırlık kuvvetidir. ${ }^{11}$ Bu kuvvetler sayesinde, asal gerilme (principal stress), eksenel gerilme (axial stress), yer değiştirmeler (displacements), deformasyon değerleri veya eşdeğer esas gerilme (equivalent principal stress) oluşturulur. Bu veriler değerlendirilmesinde, incelenen malzemenin mekanik özellikleri dikkate alınır. Kemik benzeri kırılgan malzemeler için önemli değerler asal gerilmelerdir. Esneyebilen nesnelerde oluşan stres değerlerinin ölçülmesi için ise Von Mises Stres değerlerinden yararlanılır. ${ }^{7}, 9$, ${ }^{12}$ Elde edilen verilerde en yüksek asal gerilim değeri (maximum principal stress), modelin en yüksek çekme gerilimini (tension stress) ve en düşük asal gerilim (minumum principal stress) ise modele ait en yüksek sıkışma gerilimini (compression stress) ifade eder. ${ }^{7,8,13}$

\section{SESA'da elemanlar ve çeşitleri}

Bir SESA modelinde yapı, analizlerin yapılabilmesi amacıyla küçük elemanlara bölünmektedir. Bu elemanlar ana yapının geometrisi ile özdeştir ve ana

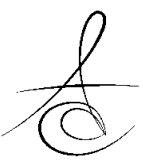


yapının her bölgesinde belirlenen mekaniksel özellikleri gösterirler. SESA'da yapısal bir modelin küçük parçalara yani elemanlara bölünme işlemine "Ağ Yapısı (Mesh)" oluşturulması denilmektedir. Hatasız ve ayrıntılı sonuçlar elde edebilmek için eleman boyutu olabildiğince küçük, hesaplamaların bilgisayar tarafından yapılabilmesi için eleman sayısının en uygun (optimal) büyüklükte seçilmesi gerekmektedir. 1, 2, 6, 7, 9, 10

SESA'da temel olarak kullanılan eleman çeşitleri şunlardır; 2, 3, 7, 13

- Çizgisel Elemanlar (Line Elements): Düğüm noktasından oluşan elemanlardır. Bu tip elemanlar uç uca eklenerek daha fazla düğüm noktasından da oluşabilirler.

- İki Boyutlu Katı Elemanlar (2D Solid Elements): Yassı yüzeylerden oluşan geometriye sahip elemanlardır. Bu tip elemanlar yüzey elemanlarıdır ve kalınlıkları sabittir. Genelde üçgen (triangular) veya eşkenar (kuadrilateral) yamuk şeklinde, 3 veya 4 düğüm noktasından oluşan elemanlardır

- Üç Boyutlu Katı Elemanlar (3D Solid Elements): Temel 3 boyutlu (3D) elemanlar, 4 yüzeyli (tetrahedral) veya 6 yüzeyli (heksahedral) şekillerdedir. (Şekil 1)

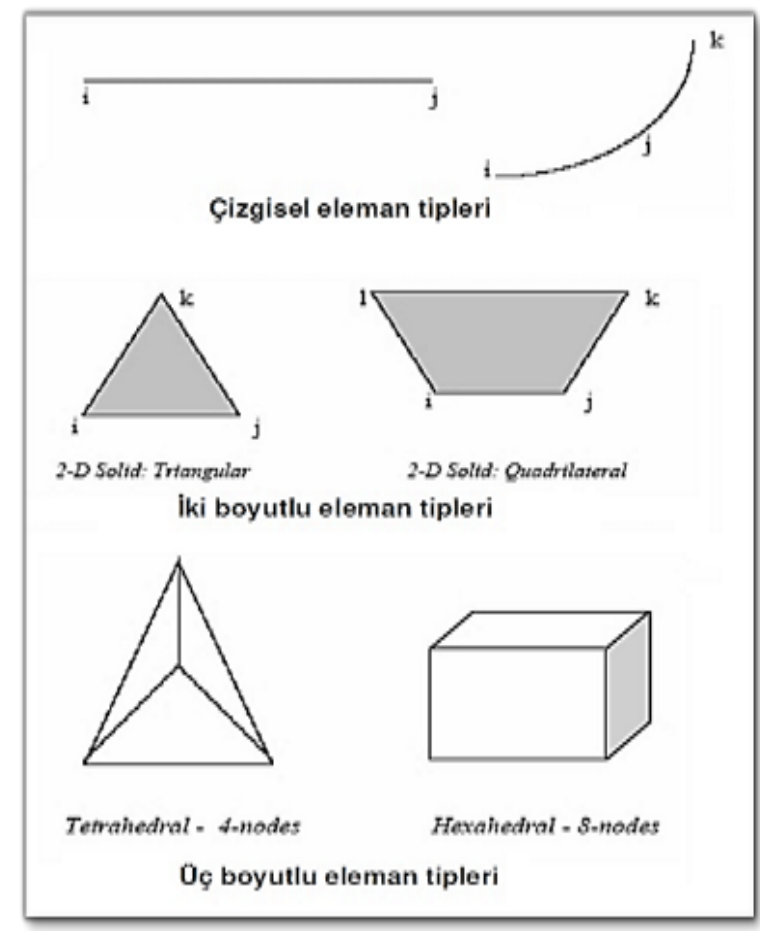

Şekil 1. SESA'da kullanılan çizgisel, iki boyutlu ve üç boyutlu eleman çeşitleri

\section{SESA ile ilgili bilinmesi gereken temel fizik kavramları}

\section{Kuvvet}

Kuvvet terimi cisimlerin hareket durumlarını veya şekillerini değiştirilebilen etkiyi tanımlar. Birimi "Newton (N)" olan kuvvetin doğrultu, yön ve şiddet gibi vektörel özellikleri bulunur. Kuvvet terimi iç ve dış kuvvet olmak üzere iki alt başlıkta incelenebilir; Dış kuvvet diğer cisimler tarafından yapılan etki olarak tanımlanırken, iç kuvvet ise cismin varsayılan çeşitli parçaları arasındaki etki ve tepki kuvvetlerine denir. Mekanik bir cismin tüm yüzeyine etki eden kuvvetler incelenirken cisim önce parçalara ayrılır ve her parça sanki diğerinden bağımsızmış gibi ayrı bir cisim gibi düşünülür. ${ }^{14}$

\section{Gerilme (stres)}

Bir cisme dışarıdan uygulanan bir kuvvette karşı, cismin birim alanında oluşturduğu tepkiye gerilme ya da stres adı verilir. Hesaplanması için "Gerilim $(S)=$ Kuvvet(F) / Alan(A)" formülü kullanılır. Uluslararası birim sisteminde gerilimin birimi " $\mathrm{n} / \mathrm{m} 2$ " olarak tanımlansa da bazı kaynaklar birim olarak PSI (pounds per square inch) ve $\mathrm{P}$ (pascal) da kullanılır. ${ }^{14}$ Diş hekimliği alanındaki çalışmalarda, incelenen nesnelerin boyutları çoğunlukla milimetre cinsinden hesaplandığı için gerilme birimi olarak 'megapaskal' (MPa veya $\mathrm{N} / \mathrm{mm} 2$ ) kullanılmaktadır. ${ }^{6,9}$

Kuvvet uygulaması sonucu cisimde üç tip gerilme oluşabilmektedir (Şekil 2). Çoğunlukla kuvvet uygulanan cisimlerde tek tip bir gerilme yerine bu üç gerilmenin bir arada bulunduğu, bileşik gerilme durumları meydana gelmektedir. Bu gerilme tipleri: ${ }^{14-16}$

- Sıkışma Gerilmesi (Compressive Stress): Cismi sıkıştırmak amacıyla, aynı doğrultuda ve farklı yönde iki kuvvetin oluşturduğu stres tipidir.

- Çekme Gerilmesi (Tension stress): Aynı doğrultuda ancak ters yöndeki iki kuvvetin, cismi uzamaya zorlayarak bütünlüğünü bozmaya yönelik oluşturduğu gerilme tipidir.

- Kesme "Makaslama" Gerilmesi (Shear Stress): Farklı düzlemde ve ters yöndeki paralel iki kuvvetin cisim üzerinde oluşturduğu gerilme tipidir. Kuvvetler cismin üzerinde etkili oldukları bölgeyi zıt yönde kaymaya zorlar. (Şekil 2) 


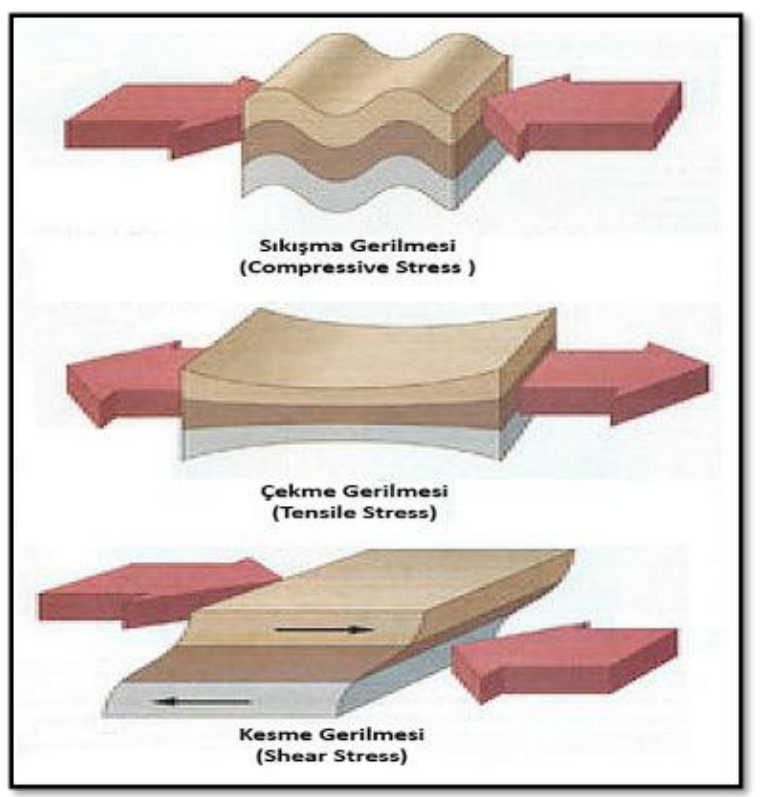

Şekil 2. Cisimlerde oluşan sıkışma, çekme ve kesme tipi gerilmelerin cisim üzerine etkileri

Üç boyutlu elemanlarda, kesme gerilimlerinin sıfır olduğu durumda asal gerilim değerleri elde edilir. Kemik benzeri kırıgan maddelerde asal gerilim değerlerinden yararlanılır. Maksimum Asal Gerilim (Pmax) pozitif bir değer olup, en yüksek gerilme stresini ifade eder, minimum asal gerilim (Pmin) ise negatif değerdir ve en yüksek sıkışma gerilimini gösterir. Bir stres elemanında hangi stres tipi daha büyük mutlak değere sahipse, o stres elemanı o stres tipinin etkisi altında kabul edilir. ${ }^{1-5,10,13}$ Örneğin nesne üzerindeki düğüm noktasında gerilme tipi stres $60 \mathrm{Mpa}$, sıkışma tipi stres - $40 \mathrm{Mpa}$ ise, o düğüm noktasında gerilme tipi stres daha etkindir ve dikkate alınması gereken ana stres değeri gerilme stresidir.

\section{Değiștirme (Gerinim, Strain)}

Şekil değiştirme, bir cisme kuvvet uygulandığında birim boyutta oluşan boyutsal değişime olarak tanımlanır. Gerilme kuvvetleri nesne üzerinde şekil değiştirmeye de sebep olurlar. Şekil değiştirme bir kuvvet değil sadece büyüklüktür. Gerinim denklemi, cisme uygulanan kuvvetin etkisi ile meydana gelen boyutsal değişimin cismin başlangıç boyutuna oranına denir ve "Gerinim (Strain) = Boyuttaki Değişim / İlk Boyut" şeklinde hesaplanır. Gerinim değeri genel olarak yüzde (\%) ile ifade edilir. 1 Strain (Gerinim) $\% 100$ uzamayı gösterirken, 1000 Microstrain (Mikrogerinim) \%0,1 uzamayı gösterir. ${ }^{15}$
Gerinim cisim üzerinde temel olarak elastik veya plastik şekilde etki gösterebilir. Elastik şekil değişimi, geçicidir ve kuvvet kalkınca cisim eski şekline döner, plastik şekil değişiminde ise oluşan şekil değişikliği kalıııdır. Bu iki durumun ortası olarak kabul edilen; "Elasto-Plastik Şekil Değiş̧irme" ise kuvvetin cisme etkisi sırasında oluşan şekil, bir miktar orijinal haline dönüyor fakat cisim yine de ilk halini alamıyorsa gerçekleşmiş olur. Cisme uygulanan kuvvet, cismin dayanabileceği gerilim kuvvetinden büyük olursa, cismin yapı taşlarını bir arada tutan kuvveti aşmış olacağı için, cisimde kopma veya kırıma meydana gelebilir. ${ }^{14}$

\section{Hooke Kanunu}

Robert Hooke tarafindan tanımlanan "Hooke Kanunu" belirli gerilme sınıları içerisinde cisimdeki gerinimin, gerilim ile doğru orantılı olarak arttığını öngörür. Bir başka deyişle bir maddenin bozulmasının, bozulmaya sebep olan kuvvetle doğru orantılı olduğunu açıklar. Gerinim ve gerilme arasındaki ilişkiyi gösteren eğri, cisme kuvvet uygulandığında cisimde ne kadar bozulma olacağını tahmin etmeye yarar. Bu eğrideki düz eğim kuvvet katsayısını ( $k$ ) verir ve cismin sertlik derecesini gösterir. Yüksek esneklik katsayısı rijit (Sert), düşük esneklik katsayısı ise esnek materyalleri tanımlar. ${ }^{14,16}$

\section{Elastiklik Katsayısı (Young's Katsayısı)}

$\mathrm{Bu}$ terimi ilk defa hesaplayan İngiliz fizikçi Thomas Young'ın ismi ile 'Young's Katsayısı' olarak da anılan, elastiklik (esneklik) katsayısl; elastikiyet sınırları içinde maddenin sertliğini yani gerinme ve gerinim arasındaki oranı gösteren bir katsayısıdır. Elastiklik katsayısı(E); Gerilmenin, birim uzamaya bölünmesi ile elde edilir. Elastiklik katsayısı farklı materyaller için farklı değerler almaktadır. Bu değer arttıkça, cismin uzamaya karşı gösterdiği direnç de artacaktır. Sert maddelerin bozulmaya karşı yüksek iç dirençe sahip olması nedeniyle elastiklik katsayıları yüksektir. Kompakt kemiğin elastiklik katsayısının yumuşak dokunun 6700 katı olması buna örnektir. ${ }^{4,6,9, ~ 14-16 ~(S ̧ e k i l ~ 3) ~}$

$$
E \equiv \frac{\text { Çekme gerilmesi }}{\text { Birim şekil değiştirme }}=\frac{\sigma}{\varepsilon}=\frac{F / A_{0}}{\Delta L / L_{0}}=\frac{F L_{0}}{A_{0} \Delta L}
$$

Şekil 3. Young katsayısının elde edilmesi (E: Young katsayıSı "Elastikiyet Katsayısı" (Paskal cinsinden), F: Cisme etki eden kuvvet, $\mathrm{A}_{0}$ : Kuvvetin etki ettiği birim alan, $\Delta \mathrm{L}$ : Cismin son uzunluğu, $\mathrm{L}_{0}$ : Cismin ilk uzunluğu) 


\section{Poisson Oran}

Poisson Oranı kuvvet uygulanan materyalin enindeki birim uzamanın, boyundaki birim uzamaya olan oranıdır. Yani Poisson oranı, bir eksendeki gerilim ile bu gerilimin diğer eksenlerde oluşturacağı deformasyonu ilişkilendiren katsayıdır. Bir nesneye çekme kuvveti uygulandığında, kuvvet yönünde uzama, kuvvete dik olan diğer boyutlarda ise kısalma meydana gelmektedir. Sıkışma kuvvetleri altında ise cismin boyu kısalırken eni kalınlaşmaktadır. Bir yöndeki uzama diğer eksenlerde kısalmayla sonuçlanacağı için negatif değer taşır, ancak mutlak değer içinde kabul edilir. Yumuşak olan materyaler çekme esnasında çapraz kesitte daha fazla azalma gösterirler ve poisson oranı daha yüksek olur. Poisson Oranı = Endeki birim uzama / Boydaki birim uzama'dır. ${ }^{14-17}$

\section{Von Mises Stresi (Gerilmesi )}

Von Mises Stresi, esneyebilir materyaller için şekil değiştirmenin başlangıı olarak tanımlanan ve kırıma dayanıklıı̆ının ölçülmesindeki analizlerde kullanılan bir değerdir. Diğer bir deyişle, Von Mises gerilmesi çeşitli matematiksel varsayımların yardımıyla elemanlar üzerindeki gerilmeler ve kesme gerilmelerinin ortalamasıdır. Von Mises stresi, cisim üzerindeki gerilme dağıııları ve yoğunlukları hakkında bilgi almak için kullanilır. İki veya üç boyutta oluşan gerilmeleri birleştirerek, tek yönde yüklenen cismin gerilme mukavemetini verir. Bu değerler analizlerde genellikle renk yelpazesi üzerinde gösterilmektedir ${ }^{16,17}$.

\section{SESA metodunda çözüm tekniği}

SESA "Parçadan Bütüne Gitme" prensibine dayalı numerik bir yöntemdir. Sonlu elemanlar; İki veya üç boyutlu yapıların bir parçası veya bir bölgesidir. Bu analiz karmaşık mekanik problemleri çözmek için önce problemleri daha küçük ve daha basit unsurlara böler ve yüzey şekil fonksiyonlarını kullanarak ara değerler elde eder. Daha sonra bu değerler problemin tümü için yorumlanır. Böylece analitik yollarla çözülmesi çok zor olan, karmaşık yapıya sahip cisimler için kurulan denklemleri kolayca çözümleyebilir. ${ }^{1-5,7,18}$

SESA'nın üç aşaması bulunur.

1. Hazırlık (Pre-proccesing) Safhası

2. Çözüm (Analiz) Safhası

3. İşlem Sonu Düzenleme (Post-processing) Safhası

\section{Hazırlık Safhası (Pre-Processing)}

Bu aşamada kısaca yapı modellenir, bilgisayara aktarımı tamamlanır ve SESA'nın temeli olan ağ modeli (mesh) oluşturulur. İlk olarak analiz yapılacak geometrik cisim taranır ve bu cisim bilgisayar ortamında CAD (Computer Aided Design) programları yardımıla modellenir. Daha sonra bu geometrik cismin elemanlara bölünebilmesi için ihtiyaç duyulan ağ yapısı (mesh) oluşturulmalıdır. Ağ yapısı yaratılmak üzere oluşturulan model yapı elemanlarına bölünür. Ağ oluşturma işlemi sayesinde, düğüm noktaları ve elemanlara ait koordinatlar belirlenmiş olur. Bu aşamadan sonra oluşturulan modele "Matematiksel Model" ismi verilir. Program, belirlenen değerlere göre, belirli bir süre sonunda düğüm noktalarını, elemanları otomatik olarak sıralar ve numaralandırır. Her bir eleman, ana yapıyı mekanik özellik ve karakter açııından taklit eder. Elemanların yapısı mümkün olduğunca basit olmalıdır. Her eleman için ayrı ayrı kuvvet dağılımları olacağından, hassas analiz yapabilmek için elemanların sayısı mümkün olduğunca fazla tutulmalıdır. Tek boyutlularda doğrular, iki boyutlularda üçgenler veya paralel kenarlar; üç boyutlularda ise dört, beş ve altı yüzlü yapılar tercih edilir. Bir boyutlu cisimler birbirine düğümlerle, iki boyutlu cisimler çizgilerle, üç boyutlu cisimler düzlemlerle sonlu elemanlara ayrılacaktır. Her durumda nesneyi temsil eden elemanlar, düğümlerle birbirine bağlanmış olur. ${ }^{1-5,19}$

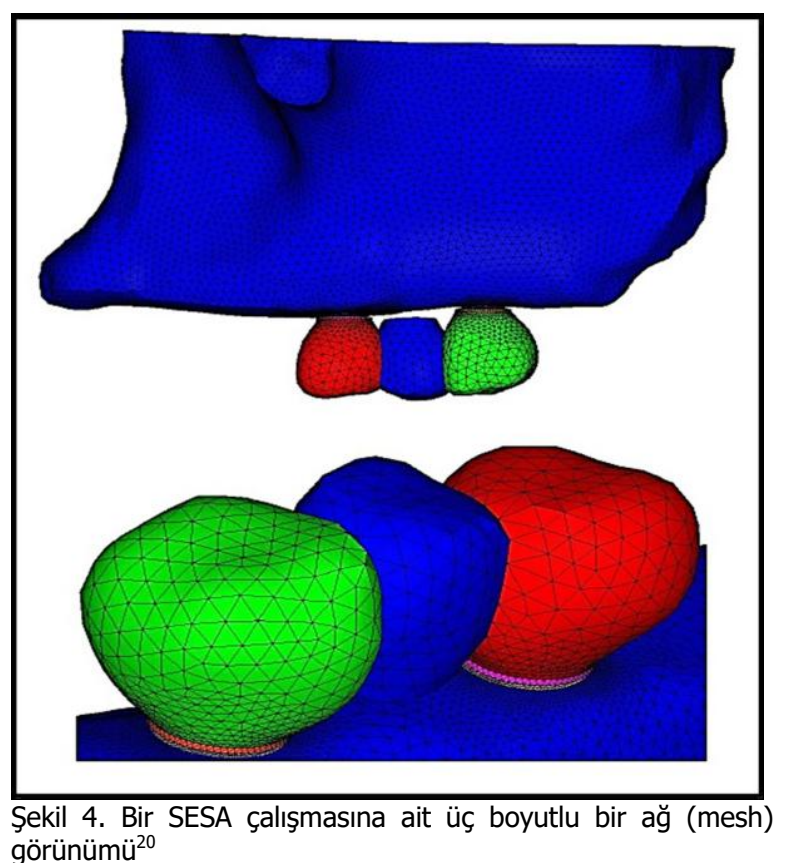

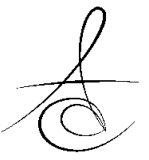




\section{Çözüm (Analiz) Safhası}

Çözüm evresindeki amaç, oluşturulan modelin her bir elemanının mekanik özelliklerini ve yükleme koşullarını tanımlamaktır. Mekanik özelliklerin belirlenmesi için elastisite modülü ve poisson oranı kullanılır ve yükleme koşullarının belirlenmesi için uygulanacak kuvvetinin yönü, büyüklüğü ve açısı tanımlanır. (Şekil 5) Modeldeki elemanların her biri ana yapının tüm özelliklerini taşıdığından, her bir elemanın yükleme altına gösterdiği tepki ana yapıyı taklit eder. Bu çözümlemeler "hareket sapması (defleksiyon)" içinde yapilır ve hareket sapması verileri gerilim, gerinim ve reaksiyonların hesaplanmasında kullanilır. Bu safhada elde edilen veriler, analizler sonrası grafik ve tabloların yapımında kullanııır. ${ }^{1-5,} 19$

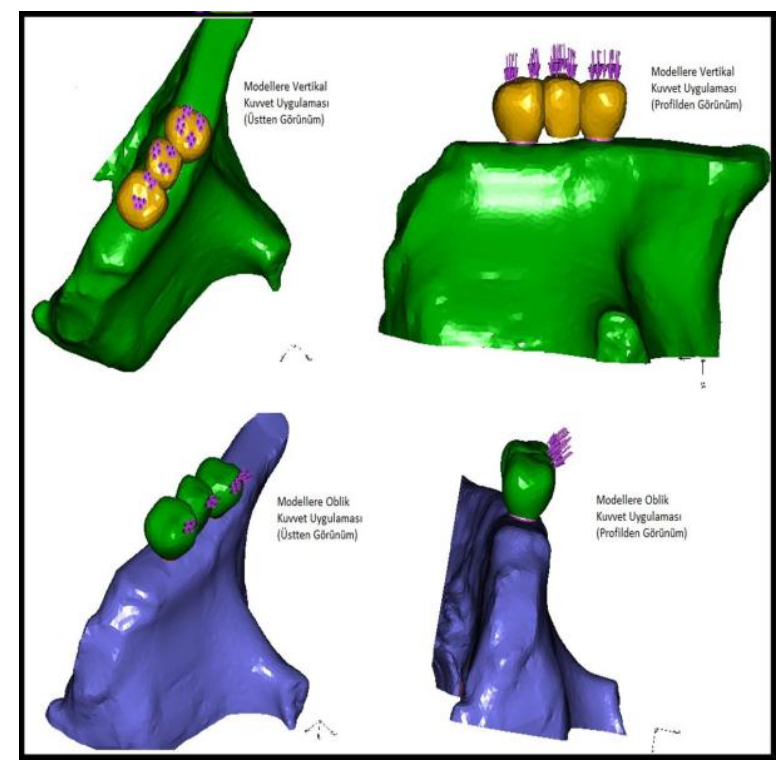

Şekil 5. Bir SESA çalışmasında hazırlanan modele uygulanan değişik yönlerdeki kuvvetler ${ }^{20}$

\section{İșlem Sonu Düzenleme (Post-Processing) Safhası}

Bir önceki safhada elde edilmiş olan analiz verilerinin çözümlenmesini içeren son aşamadır. Bu aşamada elde edilen veriler, tablolar ve grafikler şeklinde sayısal ve teorik değerler biçimindedir. Bu nedenle, verilerin bu şekilde yorumlanması zor olacaktır. Bu verileri kolayca değerlendirebilmek için, bilgisayar ortamında yapıların kuvvetler altındaki geometrik sapması, gerilmelerin dağııımı ve farklı veriler hakkında animasyonlar elde edilmelidir. Analiz sonuçlarında negatif ve pozitif değerler elde edilir. Pozitif değerler, gerilme tipi stresleri, negatif değerler, sıkışma türündeki gerilmeleri belirtir. Bir eleman üzerinde daha büyük mutlak değere sahip olan stres tipi, o eleman üzerinde etkin olarak kabul edilir. ${ }^{1-5,} 19$

Uygulanan kuvvetler sonucunda oluşan stresler iki başlıkta incelenir; Normal stresler gerilme ve sıkışma stresleridir ve $\sigma$ ile sembolize edilir, kesme tipi stresler ise $\mathrm{T}$ ile sembolize edilir. Sıkışma tipi kuvvetler kemikimplant ara yüzeyinde daha sıkı bir ilişki oluşmasına sebep olurken, gerilme ve kesme tipi kuvvetler ise kemik-implant ara yüzeyinde nesnelerin birbirinden uzaklaşmasına sebep olan yıkııı kuvvetlerdir. Dental implant-protez sisteminde en iyi tolere edilen kuvvetler sıkışma tipi kuvvetlerdir. ${ }^{7,8,12}$

Üç boyutlu bir elemanda, en büyük stres değeri, tüm kesme tipi stres bileşenleri sıfır olduğunda oluşur. $\mathrm{Bu}$ koşullar altında normal streslere; Asal stres (Principle Stress) denir. ${ }^{2,4,5}$

Principle Stress (Asal Stres) üç çeşittir:2, 4, 5

1. Maksimum Asal Stres (Maximum Principle Stress) : En yüksek gerilme stresini ifade eden pozitif bir değerdir. Genellikle Pmax olarak kısaltılır, simgesi $(\sigma 1)^{\prime} \mathrm{dir}$

2. Ara Asal Stres (Intermediate Principle Stress) $(\sigma 2)$ : Ara asal stres değerini gösterir.

3. Minumum Asal Stres (Minumum Principle Stress): En yüksek sıkışma stresini ifade eden negatif bir değerdir. Genellikle Pmin olarak kısaltıır ve simgesi ( $\sigma 3)^{\prime}$ dir.

Bu değerler şu şekilde sıralanabilir: $\sigma 1>\sigma 2>\sigma 3$

\section{SESA'nın avantajları ${ }^{21,22}$}

1. Bir cisim karmaşık bir geometrik şekle sahip olsa bile, SESA yöntemi ile güvenle analiz edilebilir.

2. Uygulanan kuvvetlerin cismin herhangi bir noktasında oluşturduğu stresler ayrı ayrı ölçülebilir.

3. Bir cisim değişik malzemelerin birleşiminden elde edilmiş ya da zamana bağlı değişken özelliklere sahip olsa bile kolaylıkla değerlendirilebilir.

4. Neden ve sonuç ilişkisine ait sorunlar, küçük bir elemanda çözümlenerek tüm sisteme ait kuvvetler ve yer değiştirmeler cinsinden formüle edilebilir.

5. Sınır şartları kolayca uygulanır.

6. SESA metodu çok yönlü ve esnek bir sistemdir. Böylece karmaşık yapılarda, sürekli ortam, saha problemlerinde ve diğer problemlerde neden-sonuç ilişkilerini hesaplamak için çok etkili bir şekilde kullanılabilir. Bu nedenle analitik ve deneysel yöntemlerden daha kesin sonuç verir. 
7. Girişimsel olmayan (Non-invasive) bir metottur.

8. Eğer gerekli görülürse çalışma kolayca ve defalarca tekrarlanabilir.

9. Doğru değerlerle, gerçeğe çok yakın modeller elde edilebilir.

\section{SESA'nın dezavantajları ${ }^{21,22}$}

1. Programların maliyeti çok yüksek ve patentlidir. Her kullanıcının yalnızca bir giriş hakkı vardır ve bu nedenle kullanılan programlar her kullanıc için ayrı ayrı lisanslanmalıdır.

2. Bu programlar sıklıkla yenilenmektedir ve daha sağlıklı sonuçlar alınması için son sürüme sahip olunmalıdır.

3. Kullanılacak malzemelerin özellikleri ve uygulanacak kuvvetlerin sisteme girişi tamamen kullanıcıya bağımlıdır ve sonuçlar farklı değerler kullanılan, araştırmadan araştırmaya değişkenlik gösterebilir.

4. Programları kullanmak için bilgisayarda oldukça iyi bir donanıma sahip olmak gerekir ve bu nedenle yüksek maliyetli yatırım gerektirir.

5. Programların kullanımı için özel eğitim ya da profesyonel destek gerekebilir.

\section{SESA metodunun güvenilirliğini etkileyen faktörler \\ SESA'da gerçeğe yakın sonuçlar elde edilme-} sinde en önemli etkenlerden biri, incelenecek cismin geometrisine oldukça yakın model hazırlama işlemidir. Matematiksel modellerin doğruluğu, seçilen eleman tipine, eleman sayısına ve eleman davranışıyla ilgili yapılan varsayımlara bağlıdır. Eleman sayısının artması bilinmeyenlerin sayısının artmasına neden olurken, sonuçların doğruluğunu arttırmaktadır. ${ }^{7-9}$

SESA çalışmalarında 3D model hazırlanması zaman ve ekonomik açıdan zor olsa da, 2D modellemeye göre sonuçları etkileyebilecek bir takım avantajları mevcuttur. Özellikle modellenecek yapının anatomisinin düzensiz olduğu ve kuvvetin uygulandığı düzlemin simetrik olmadığı durumlarda, 3D modelde gerçeğe daha yakın modeller elde edilmesi ve model üzerinde bütün streslerin ayrıntılı şekilde gösterilebilmesi, sonuçların doğruluğu açısından olumlu etkilere sahiptir $^{23,24}$. Bu konu hakkında Meijer ve ark. ${ }^{23}$ yaptıkları çalışmada aynı senaryoyu 2D ve 3D SESA metotlarında canlandırmışlardır. Bu çalışmalarına dayanarak, 3D model üzerinde uygulanan bir analizin daha ger- çekçi ve hassas sonuçlar verdiği mümkün olduğunca tercih edilmesi gerektiğini belirtmişlerdir. 2D SESA'nın kısa sürede fakat yalnızca genel bir sonuç elde edildiğini bildirmişlerdir. Benzer şekilde Ismail ve ark. ${ }^{24} 2 \mathrm{D}$ ve 3D SESA'yı karşılaştırdıkları çalışmalarında 2D analizlerin asal gerilme dağılımlarının incelenmesinde yeterli olduğunu ancak normal gerilme dağılımlarında yetersiz kalabileceğini bildirmişler ve $3 D$ model kullanımının avantajlarını vurgulamışlardır.

Meijer $^{23}$ ve Clelland ${ }^{25}$ 3D SESA yönteminin başarısının, sayısal modellerdeki elemanların ve düğümlerin sayısıyla doğru orantılı olduğunu rapor etmişlerdir. Buna karşın eleman ve düğüm sayılarının artırılması daha güçlü bir bilgisayar donanımı gerektirmekte ve analiz süresini uzatmaktadır. Bu nedenle literatürdeki çalışmaların çoğunluğunda eleman ve düğüm sayısının sınırlandırıldığı görülmektedir. ${ }^{24-27}$

Son yıllarda dijital görüntüleme tekniklerinin gelişmesiyle, anatomik olarak daha uygun modellerin oluşturulması için daha etkili yöntemler geliştirilmiştir. $\mathrm{Bu}$ teknikler bilgisayarlı tomografi görüntülerinden alınan verileri 2 veya 3 boyutlu görüntüye veya manyetik rezorans görüntüleme (MRG) yoluyla elde edilen verileri SESA mesh yapılarına çeviren özel yazılımlardır. Kemik yoğunluğu ölçülerinden elde edilen bazı materyal özellikleri kemik-implant sisteminin geometrisini oluşturmakta daha kesin modellemeye olanak sağlar. Gelecekte gelişen dijital görüntüleme teknikleriyle kişiye özel SESA modellerinin oluşturulması mümkün olacaktır. ${ }^{6,7,9,13}$

\section{SESA'nın dental implantolojide kullanımı}

Son yıllarda SESA; implant ve çevre kemik üzerinde oluşan streslerin etkilerini araştırmak amacıyla giderek artan bir kullanıma sahiptir. Çiğnemeyle oluşan vertikal ve transvers yükler aksiyel kuvvetlerin ve bükülme hareketlerinin oluşmasına sebep olarak implant ve çevre kemikte stres meydana getirmektedir. İmplant başarısındaki esas faktör gelen kuvvetlerin kemiğe nasıl iletildiğidir. İmplant aracılığıyla kemiğe iletilen kuvvet miktarı yüklemenin türüne, implantkemik birleşimine, implantın uzunluk ve çapına, implant yüzey özelliklerine, protetik yapıya ve çevre kemiğin niteliğiyle niceliğine bağlıdır. SESA, implantın kortikal kemikle ve apeks çevresindeki trabeküler kemikle ilişkili olan alanlardaki stres dağılımının değerlendirilmesine olanak tanır ${ }^{7,8,13,28-31}$. Weinstein ve ark. ${ }^{32} 1976$ yılında SESA'nın dental implantolojide ilk kez kullanmasıyla 
birlikte bu uygulama hızla yayılmıştır.

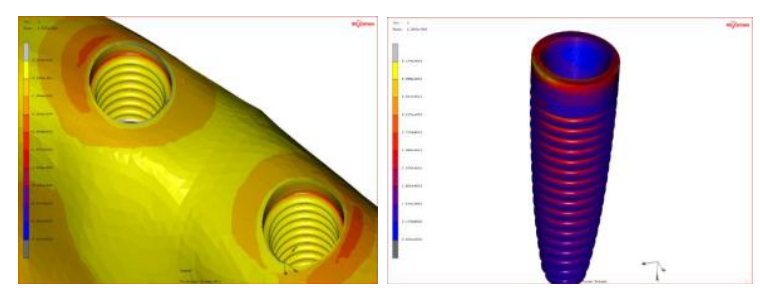

Şekil 6. Bir SESA çalışmasına ait stres oluşumları renk yelpazesi ile gözlenen, üzerinde implant yuvaları bulunan trabeküler kemik ve dental implant ${ }^{20}$

İmplantlarda, oral fonksiyonlar sırasındaki kesintili kuvvetler, kemikte yetersiz mekanik uyarıdan çok, yüksek gerilim ve gerinim ile sonuçlanan aşırı yüklenme oluşturarak kemik rezorpsiyonuna yol açar. Kemikte oluşan gerinimin, strain gauge iğneleri ile hastalardan doğrudan ölçülmesi pratik olmadığından SESA gibi dolaylı matematiksel yaklaşımlar gerinim, gerilim ve deformasyon gibi değerlerin hesaplanmasında sıklıkla kullanilır. ${ }^{13,33}$

Fanuscu ve ark. ${ }^{34} 2004$ ylında maksilla posterior bölgede implant uygulamaları sırasında sıklkkla başvurulan sinüs lifting işlemi ile ilgili SESA çalışması gerçekleştirmiştir. Zampelis ve ark. ${ }^{35}$ açılı yerleştirilen implantlarla ilgili bir SESA çalışması yapmışıı.Sannino ${ }^{36}$ All-on-4 implant konsepti ile ilgili bir SESA çalışması gerçekleştirmiştir. Kısa implantlar ${ }^{37}$, dental implant üstü kantilever uzantılar ${ }^{38}$, kişiye özel implant tasarım ${ }^{39}$, fibula greftine yerleştirilen implantlar $^{40}$, zigoma implantlari ${ }^{41}$ gibi dental implantolojinin birçok alanıyla ilgili SESA ile yapılmış literatürde yüzlerce çalışma bulunmaktadır ve neredeyse yapılabilecek çalışmalar ancak hayal gücü ile sınırlandırılabilmektedir.

Diğer yönden in vitro bir araştırma metodu olan SESA'nın dental implantoloji alanındaki güvenilirliği hakkında birçok çalışma yapılmıştır. Baiamonte ve ark. $^{42}$ tarafından SESA çalışmalarııın dental implantoloji açısından güvenilirliğini test etmek üzere yapılan bir çalışmada, osseointegre titanyum implant yerleştirilmiş maymun mandibulasında oluşan gerinim değerleri hem in vitro hem SESA çalışmalarıla değerlendirilmiştir. Çalışmacılar elde edilen sonuçların yüksek oranda birbiriyle örtüşsmesine dayanarak SESA yönteminin dental implantolojide güvenli bir şekilde uygula- nabileceği sonucuna varmışlardır. Dental implantlar hakkında yapılan çalışmalarda, stres dağıımlarının ölçülebilmesi için SESA yönteminden başka gerinim ölçme (strain gauge) ve fotoelastik yöntemler de yaygın olarak kullanılmaktadır. ${ }^{33}$ de Vree ve ark. ${ }^{43}$ fotoelastik yöntemin stres yoğunlaşması ve yerleşimi ile ilgili niteleyici bilgi sağlamasına karşın SESA'ya kıyasla sınırlı sayısal veri sağladığını belirtmişlerdir. Gerinim ölçerin ise yalnızca yerleştirildiği noktalarda kesin deformasyon verilerini verdiği bilinmektedir. Akça ve ark. ${ }^{33}$ yaptıkları bir çalışmada dental implant üzerinde meydana gelen streslerin incelenmesinde SESA ile gerinim ölçer analiz yöntemini kıyaslamışlardır. Her iki yöntemde de uygulanan kuvvetler altında meydana gelen stres miktarları konusunda yakın sonuçlar elde edilmiş fakat modelleme açısından SESA metodu, daha hassas ve ayrıntılı sonuclara izin verdiği için daha avantajı bulunmuştur.

SESA çalışmalarında elastisite modülü ve poisson oranı ile nitelendirilen çene kemiğinin maddesel davranışının homojen, izotropik ve linear elastik olduğunu varsayılır. Bu nedenle SESA ile yapılan çalışmaların en önemli dezavantajı, canlı dokuları taklit etmek için doğal koşullarda değişiklik gösteren kortikal kemik kalınlığı ve trabeküler kemik yoğunluğu gibi bir dizi faktörün sabit olarak düşünülme zorunluluğudur. Günümüz teknolojisi ile doğal koşulların tüm ayrıntılarını bilgisayar modeline aktarmak mümkün değildir. ${ }^{1}, 6,7,13$

SESA'da değerler elemanların sadece üst yüzeyindeki düğüm noktalarından veya elemanın tüm düğüm noktalarından okunabilir. Ancak çene kemiği, dental implantlar ve protetik üst yapı protezleri gibi karmaşık yapıya sahip modellerde sadece üst yüzeydeki değerleri okumanın sonuçların yanlış yorumlanmasına neden olabileceği yapılan çalışmalarda bildirilmiştir.7, 8, 28, 29 SESA çalışmalarında amaç, yük uygulaması altında cismin bütünlüğünün ilk önce hangi noktada bozulacağının araştırımasıdır. Kemik gibi kırılgan özellikte dokuların stres değerlerini daha güvenilir biçimde veren Asal Stres değerlerinden yararlanilırken, titanyum gibi materyallerde daha güvenli sonuç veren Von Mises stress değerlerinden faydalanı.lır. ${ }^{7} 8$ Stres analizlerinde matematiksel hesaplamalar sonucu elde edilen numerik değerler varyasyon göstermediğinden, sonuçların istatistiksel olarak değerlendirilmesi rutin yapılması gereken bir işlem değildir. Ancak bu sonuçlardan klinik uygulamalarda faydalanabilmek için sonuçlar dikkatli bir şekilde incelenmeli ve yorumlanmalıdır. ${ }^{2,3,5,9}$

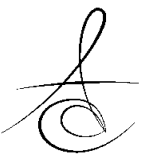




\section{SONUÇ}

Günümüze kadar dental implantoloji alanındaki araştırmalarda yaklaşık 40 yıllık bir geçmişe ulaşan SESA yöntemi, özellikle klinik deneylerde birebir şartlarda tekrarlanması mümkün olmayan deneylerin, farklı senaryolarla sınırsız tekrarlanabilmesine olanak vermesi ve etik nedenlerle hastalar üzerinde uygulanması mümkün olmayan deneylerin etik sorumluluk olmaksızın yapılabilmesine olanak sağlaması açısından kullanışı bir metottur. Üstelik birçok araştırmada, alternatif in vitro yöntemlere olan üstünlüğü ya da benzer sonuçlar verdiğide gösterilmiştir. Yüksek donanımı bilgisayarlara erişimin de maddi olarak günümüzde daha mümkün olması SESA yönteminin uygulanabilmesini kolaylaştıran bir diğer faktördür. Ancak herşeye rağmen unutulmamalıdır ki günümüz teknolojisi ile doğal koşulların tüm ayrıntılarını dinamik olarak bilgisayar modeline aktarmak mümkün değildir. Bu nedenle gelecekte üstün bilgisayar teknolojileri geliştirilene dek, mühendislik alanından farklı olarak canlı, biyolojik dokular üzerinde yapılan tıbbi SESA araştırmaları her zaman klinik çalışmalarla doğrulanmalıdır.

'Bu makale yazarlarından hiçbirinin makalede bahsi geçen konu veya malzemeyle ilgili herhangi bir ilişkisi, bağlantısı veya parasal çıkar durumu söz konusu değildir'.

Sercan Küçükkurt: ORCID NO: 0000-0002-4095-957X

\section{KAYNAKLAR}

1. Srirekha A, Bashetty K. Infinite to finite: an overview of finite element analysis. Indian J Dent Res. 2010;21:425-32.

2. Bathe KJ. Finite element procedures: Klaus-Jurgen Bathe; 2007.

3. Moaveni S. Finite element analysis theory and application with ANSYS. 3 ed: Prentice Hall; 2007.

4. Chandrupatla TR. Finite element analysis for engineering \& technology. Orient Blackswan 2003.

5. Hughes TJR. The Finite element method: linear static and dynamic finite element analysis: Dover Publications; 2000.

6. Shetty P, Hegde AM, Rai K. Finite element method-an effective research tool for dentistry. J Clin Pediatr Dent 2010;34:281-5.

7. Jianping $G$, Weiqi $Y$, Wei $X$. Application of the finite element method in implant dentistry: Springer; 2008.
8. Van Staden RC, Guan H, Loo YC. Application of the finite element method in dental implant research. Comput Method Biomec -2006; 9:257-70

9. Geng JP, Tan KB, Liu GR. Application of finite element analysis in implant dentistry: a review of the literature. J Prosthet Dent 2001;85:585-98.

10. Ebrahimi F. Finite Element Analysis: New trends and developments: Intech; 2012.

11. Bölükbaşı $N$, Koçak $A$, Özdemir $T$. İmplant konumlarinin anterior maksillada oluşturacaklari etkilerin biyomekanik olarak araştirilmasi. İstanbul Üniv Diş Hek Fak Derg 2012; 46:18-28.

12. DeTolla $D$, Andreana $S$, Patra $A$, et al. The role of the finite element model in dental implants. J Oral Implantol 2000; 26: 77-81.

13. Wakabayashi $N$, Ona $M$, Suzuki $T$, Igarashi $Y$. Nonlinear finite element analyses: advances and challenges in dental applications. J Dent 2008; 36:463-71.

14. Avallone E, Baumeister T, Sadegh A. Marks' standard handbook for mechanical engineers. 11 ed. New York: McGraw-Hill; 2006.

15. Donald R. Askeland, Pradeep P. Fulay, Wendelin J. Wright. The science and engineering of materials. 6th ed: CL Engineering; 2010.

16. Shigley JE, Mischke CR, Budynas RG. Mechanical engineering design (International Edition): McGraw Hill Higher Education; 2003.

17. Adıgüzel Ö. Sonlu elemanlar analizi: derleme Bölüm I: dişhekimliğinde kullanım alanları, temel kavramlar ve eleman tanımları. Dicle Dişhek Derg 2010;11:18-23.

18. Baran NM. Finite Element Analysis on microcomputers: Mcgraw-Hill; 1991.

19. Geramy A, Morgano SM. Finite element analysis of three designs of an implant-supported molar crown. J Prosthet Dent 2004; 92:434-40.

20. Küçükkurt S. Dental implant uygulaması amacıyla intiyaç duyulan sinüs tabani yükseltme işlemi ve alternatif tedavi seçeneklerinin sonlu elemanlar analiz yöntemi ile karşılaştıııması. Ankara: Gazi Üniv; 2014.

21. Ramoğlu S, Ozan O. Diş hekimliğinde sonlu elemanlar stres analiz yöntemi. Atatürk Üniv Diş Hek Fak Derg 2014;Supp: 9:175-80.

22. Taşkınsel E, Gümüş HÖ. Sonlu elemanlar stres analizi ve restoratif diş hekimliğinde kullanimi. Atatürk Üniv Diş Hek Fak Derg 2014;Supp 8:131-5.

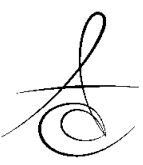


23. Meijer H, Starmans F, Bosman F, Steen W. A comparison of three finite element models of an edentulous mandible provided with implants. J Oral Rehabil 1993;20:147-57.

24. Ismail Y, Pahountis L, Fleming J. Comparison of two-dimensional and three-dimensional finite element analysis of a blade implant. Int J Oral Implantol 1987;4:25-31.

25. Clelland N, Ismail $Y$, Zaki H, Pipko D. Threedimensional finite element stress analysis in and around the Screw-Vent implant. Int J Oral Maxillofac Implants 1991 Winter; 6:391-8.

26. Clelland N, Lee J, Bimbenet O, Brantley W. A three-dimensional finite element stress analysis of angled abutments for an implant placed in the anterior maxilla. J Prosthodont 1995; 4:95-100.

27. Kregzde M. A method of selecting the best implant prosthesis design option using three-dimensional finite element analysis. Int J Oral Maxillofac Implants 1993; 8:662-73.

28. Li T, Hu K, Cheng L. Optimum selection of the dental implant diameter and length in the posterior mandible with poor bone quality - A 3D finite element analysis. Appl Math Model 2011; 35: 44656.

29. Liang K, Zexu G, Kaijin H. Optimization of the implant diameter and length in type $B / 2$ bone for improved biomechanical properties: A threedimensional finite element analysis. Adv Eng Softw 2009; 40: 235-40.

30. Huang $H$, Fuh $L$, Ko C. Biomechanical effects of a maxillary implant in the ougmented sinus: a three dimensional finite element analysis. Int J Oral Maxillofac Implants 2009; 24: 455-62

31. Simşek B, Erkmen E, Yilmaz D, Eser A. Effects of different inter-implant distances on the stress distribution around endosseous implants in posterior mandible: a 3D finite element analysis. Med Eng Phys 2006; 28:199-213.

32. Weinstein AM, Klawitter JJ, Anand SC, Schuessler R. Stress analysis of porous rooted dental implants. J Dent Res. 1976; 55: 772-7.

33. Akça K, Cehreli M, Iplikçioglu H. A comparison of three-dimensional finite element stress analysis with in vitro strain gauge measurements on dental implants. I Int J Prosthodont 2002;15:115-21
34. Fanuscu MI, Vu HV, Poncelet B. Implant biomechanics in grafted sinus: a finite element analysis. J Oral Implantol 2004; 30: 59-68.

35. Zampelis A, Rangert B, Heijl L. Tilting of splinted implants for improved prosthodontic support: a two-dimensional finite element analysis. J Prosthet Dent 2007; 97:S35-43.

36. Sannino G. All-on-4 concept: a 3-dimensional finite element analysis. J Oral Implantol. 2015;41:16371.

37. Song HY, Huh YH, Park CJ, Cho LR. A two-shortimplant-supported molar restoration in atrophic posterior maxilla: A finite element analysis. J Adv Prosthodont 2016; 8:304-12.

38. Akca K, Iplikcioglu H. Finite element stress analysis of the effect of short implant usage in place of cantilever extensions in mandibular posterior edentulism. J Oral Rehabil 2002;29:350-6.

39. Chen J, Zhang Z, Chen X, et al. Design and manufacture of customized dental implants by using reverse engineering and selective laser melting technology. J Prosthet Dent 2014; 112: 1088-95

40. Nesappan T, Ariga P. Comparison of stresses around dental implants placed in normal and fibula reconstructed mandibular models using finite element analysis. J Clin Diagn Res 2014; 8: ZC4550.

41. Wen $H$, Guo $W$, Liang $R$, et al. Finite element analysis of three zygomatic implant techniques for the severely atrophic edentulous maxilla. J Prosthet Dent 2014; 111: 203-15.

42. Baiamonte $T$, Abbate M, Pizzarello $F$, et al. The experimental verification of the efficacy of finite element modeling to dental implant systems. J Oral Implantol 1996;22:104-10

43. de Vree JH, Peters MC, Plasschaert AJ. A comparison of photoelastic and finite element stress analysis in restored tooth structures. J Oral Rehabil 1983; 10: 505-17.

\section{Yazışma Adresi}

Sercan KÜÇÜKKURT

Istanbul Aydın Üniversitesi

Diş Hekimliği Fakültesi

Ağız, Diş ve Çene Cerrahisi ABD, ISTANBUL - TÜRKIYYE

e-mail: skucukkurt@gmail.com 